
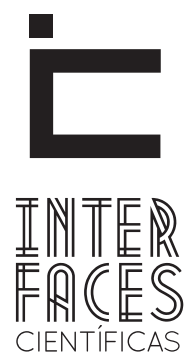

EDUCAÇÃO

ISSN IMPRESSO 2316-333X

E- ISSN 2316-3828

DOI 10.17564/2316-3828.2016v4n2p23-32

\title{
INGLÊS: A LÍNGUA DA INTERNACIONALIZAÇÃo
}

Ana Lúcia Simões Borges Fonseca ${ }^{1}$

\section{RESUMO}

A internacionalização é uma das metas em todos os setores das instituições de ensino superior do Brasil, seja na graduação ou nos programas de pós-graduação, haja vista a crescente oferta e a procura por exames de proficiência, como o Test of English as a Foreign Language (TOEFL), e os exames de proficiência na pós-graduação. A análise de uma série de dados empíricos de 1998, ano em que começa a ser aplicado o Exame Nacional do Ensino Médio (ENEM), até 2013, mostra o relevo da língua estrangeira moderna e a escolha dos alunos, pontuando a seguinte avaliação: a de motivação e relevância atribuída à língua. A reflexão e a discussão propostas acerca da (não) relevância do ensino de inglês apresentam, portanto, uma situação dissonante, qual seja, para a graduação e pós-graduação, no
Brasil, a Língua Inglesa ocupa um espaço de prestígio e hegemonia. Contudo, na educação básica, por evidência da escolha dos discentes acerca da língua estrangeira na prova do ENEM, vemos a emergência do espanhol. Objetivamos, pois, analisar qual o papel do inglês e que motivações levam um aluno a escolhê-lo (ou não) em avaliações oficiais, em exames para estudos em nível de pós-graduação e na escolha do país/língua no Programa Ciência sem Fronteiras. Em suma, relevar a importância do ensino de inglês desde as séries iniciais possibilita a abertura de espaços para debates e ações articuladas que levem ao estabelecimento de uma política linguística explícita e traduzida às especificidades de uma dada comunidade. 


\section{PALAVRAS-CHAVE}

Língua Inglesa. Planejamento Linguístico. Políticas Públicas.

\section{ABSTRACT}

Internationalization is one of the goals in all sectors of the higher education institutions, be it in the graduation courses, be it in the post-graduation programs, considering the growing supply and demand for proficiency exams, such as the Test of English as a Foreign Language (TOEFL), and for the proficiency exams applied in post-graduation courses. The analysis of empirical data from 1998, the year in which the Exame Nacional do Ensino Médio (ENEM) started to be applied, until 2013, shows the prominence of the modern foreign language and students' choice, by pointing to the following evaluation: motivation and relevance given to the language. The reflection and discussion proposed about the (non) relevance of the teaching of English shows a dissonant situation, that is, for the graduation and post-graduation courses in Brazil, the English language occupies a position of prestige and hegemony. However, in the basic education, due to the

\section{RESUMEN}

La internacionalización es uno de los objetivos en todos los sectores de instituciones de educación superior en Brasil, ya sea en los programas de posgrado universitario o, dada la creciente oferta y la demanda de pruebas de competencia, como Test of English as a Foreign Language (TOEFL) y exámenes de competencia en la escuela de posgrado. El análisis de una serie de datos empíricos a partir de 1998, año en que comienza a aplicar el Exame Nacional do Ensino Médio (ESMS), de 2013, muestra la relevancia de la lengua extranjera moderna y la elección de los estudiantes, puntuando la siguiente evaluación: motivación y relevancia atri- evidence shown by the students' choices of the foreign language at ENEM, we see the emergence of Spanish. Therefore, our objective is to analyze what the role of the English language is and what motivations make a student to choose it (or not) in official exams, in exams at the post-graduation courses and in their choices of the country /language in the Program Science without Borders. In short, to highlight the importance of the teaching of English since the initial grades leverages the opening of spaces for debates and articulated actions, which lead to the establishment of an explicit language policy that is in accordance with the specificities of a given community.

\section{KEYWORDS}

English Language. Linguistic Planning. Public Policies.

buida al lenguaje. Por lo tanto, la reflexión y el debate sobre la (no) relevancia propuestas de la enseñanza del Inglés tiene una situación disonante, es decir, de pregrado y posgrado en Brasil, el idioma Inglés ocupa un espacio de prestigio y hegemonía. Sin embargo, en la educación básica, para la prueba de selección de los estudiantes acerca de la lengua extranjera en el examen ENEM, vemos el surgimiento de español. Por lo tanto, nuestro objetivo es considerar el papel de Inglés y motivaciones que hacen un estudiante elegirlo (o no) en las evaluaciones oficiales, exámenes para los estudios de posgrado y en la elección del país/idioma 
en el Programa Ciência sem Fronteiras. En resumen, revela la importancia de la enseñanza de Inglés desde los años iniciales, que permite la apertura de espacios para el debate y las acciones conjuntas que conduzcan al establecimiento de una política de lenguaje explícito y traducidos a las características específicas de una determinada comunidad.

\section{INTRODUÇ̧̃̃O}

A situação do inglês, objeto deste estudo, desperta a atenção no que tange ao seu lugar em relação às outras línguas e a outros saberes e, sobretudo, no tocante às suas finalidades, à sua histórica instabilidade nos currículos, à indefinição do seu status e, por conseguinte, a pouca importância que lhe é dada no sistema escolar brasileiro, o mesmo acontecendo com as demais línguas estrangeiras.

No entanto, ao contrário da situação que vemos no nosso sistema de ensino, a internacionalização destaca a importância do inglês no momento em que se constitui em uma das metas em todos os setores das instituições de ensino superior do Brasil, seja na graduação ou nos programas de pós-graduação, conforme nos revelam, por exemplo, a crescente oferta e a procura por exames de proficiência, como o Test of English as a Foreign Language (TOEFL), e os exames de proficiência na pós-graduação.

Em observância a esse quadro, analisamos uma série de dados empíricos de 1998, ano em que começa a ser aplicado o Exame Nacional do Ensino Médio (ENEM), até 2013, os quais nos mostram o relevo da língua estrangeira moderna e a escolha dos alunos, pontuando a seguinte avaliação: a de motivação e relevância atribuída à língua.

A reflexão e a discussão propostas acerca da (não) relevância do ensino de inglês apresentam, portanto, uma situação dissonante, qual seja, para a graduação e pós-graduação, no Brasil, a língua inglesa ocupa um

\section{PALABRAS CLAVE}

Idioma Inglés; Planificación lingüística; Políticas públicas.

lugar de prestígio e hegemonia; na educação básica, por evidência da escolha dos discentes acerca da língua estrangeira na prova do ENEM, vemos a emergência do espanhol.

Sabendo, pois, ser a internacionalização das instituições de ensino superior (IES) requisito para que haja atualização em nível mundial e, sobretudo, para que a qualidade do ensino e da pesquisa seja aprimorada, desde as séries iniciais, faz-se importante e necessário analisar qual o papel do inglês e que motivações levam um aluno a escolhê-lo, ou não, em avaliações oficiais, em exames para estudos em nível de pós-graduação e na escolha do país/língua no Programa Ciência sem Fronteiras.

Os resultados preliminares desta investigação apontam a necessidade de que a inclusão curricular da língua inglesa ocorra desde as séries iniciais, bem como a necessidade de pensarmos em políticas linguísticas/públicas que possam produzir relações mais igualitárias em nossa sociedade.

\section{INGLÊS: A LÍNGUA DA GRADUAÇ̃̃O E PÓS-GRADUAÇ̃̃O}

A internacionalização é uma das metas em todos os setores das instituições de ensino superior no Brasil, seja na graduação ou nos programas de pós-graduação, haja vista, por exemplo, a crescente oferta e a 
procura por exames de proficiência, como o TOEFL, e os exames de proficiência na pós-graduação.

Coutelle (2015) atesta que o interesse internacional, materializado pela presença cada vez mais constante de agências de vários países no Brasil, tende a impulsionar o movimento de internacionalização no âmbito de instituições, sejam elas públicas ou privadas. Para as IES, o processo só tende a gerar valor, pois, segundo ele, as instituições com programas bem estruturados ganham pontos nas avaliações do Ministério da Educação e nos diversos rankings privados, além de aumentar a procura dos alunos pela oferta de uma formação mais completa, inclusive com horizontes profissionais fora do Brasil. Conclui o autor que as parcerias proporcionam o intercâmbio de ideias, pesquisas inovadoras e soluções para problemas mais complexos, o que impacta diretamente a qualidade das experiências acadêmicas.

Mediante o exposto, o Governo Federal vem investindo na internacionalização das IES por intermédio da língua inglesa e do TOEFL. Consoante comunicado enviado pelo Presidente da Coordenação de Aperfeiçoamento de Pessoal de Nível Superior (CAPES) e pelo Secretário de Educação Superior aos reitores e pró-reitores dos programas de pós-graduação das Instituições Federais de Ensino Superior (IFES), aos 25 dias do mês de abril de 2014, versando sobre a aplicação de testes de proficiência em inglês Test of English as a Foreign Language/Institutional Testing Program (TOEFL/ITP), fica evidenciada a relevância do aprendizado desta língua como a que propiciará a promoção da internacionalização das IES brasileiras e ditará quais deverão ser as decisões tomadas pelo Ministério da Educação e Cultura (MEC) a partir dos resultados que advirão da aplicação e dos resultados obtidos nesses exames.

Segundo o comunicado, as decisões a serem tomadas pelo MEC a partir da aplicação dos exames de proficiência são: a) Definição dos recursos orçamentários a serem alocados a partir do ano de 2015, com vistas a permitir maior estruturação institucional das IES públicas no intuito de facilitar sua internacionalização;

b) Priorização de matrícula em cursos presenciais de língua inglesa para os alunos que fizerem o teste de diagnóstico nos Núcleos de Línguas (NUCLIs) das IES participantes do Programa Inglês sem Fronteiras da Secretaria de Educação Superior (SESu);

c) Possibilidade de aceitação do referido teste nos processos de proficiência para ingresso e conclusão em cursos de pós-graduação dessa instituição;

d) Possibilidade de aceitação do referido teste no processo de concessão de bolsas aos alunos a serem selecionados para a Prova Jovens Talentos;

e) Priorização de estudantes para recebimento de senhas para acesso ao Programa My English Online da Capes;

f) Estímulo às inscrições no Ciência Sem Fronteiras (CSF) dos alunos testados nesses exames para efeito de classificação nas seleções do CSF. Ainda conforme o documento há uma exigência quanto ao teste TOEFL/ITP ser aceito como prova de proficiência em inglês para os alunos ingressantes nos cursos de pós-graduação. 0 item número quatro do comunicado preconiza a finalidade do programa: “[...] permitindo que o governo por meio dessa ação tenha conhecimento real da capacidade de proficiência da língua inglesa dos alunos de graduação e pós-graduação e, consequentemente, possa delinear políticas que atendam às necessidades das IES públicas brasileiras”.

Com isso, o MEC vem, desde 2012, disponibilizando provas de proficiência em inglês, gratuitamente, para alunos de graduação, mestrado e doutorado das IES, o que também acontece na Universidade Federal de Sergipe (UFS), onde, nas novas demandas de pro- 
vas da instituição, os técnicos e professores também podem fazer tais avaliações sem que lhes seja repassado quaisquer ônus.

Programas governamentais como o CSF e o Idioma sem Fronteiras, amplamente divulgados nas IES de todo o país, evidenciam o caráter hegemônico da língua inglesa, requisito primordial para a ascensão educacional e, por tabela, profissional e econômica. Afinal, os que almejam fazer parte das ações desses programas sabem que a não obtenção de boas notas no TOEFL não somente os exclui, impossibilitando-os de pleitear vagas para os cursos presenciais, mas também os impedem de concorrerem às bolsas para se afastarem do país em programas como o CSF, que busca promover a consolidação, expansão e internacionalização da ciência e tecnologia, bem como da inovação e competitividade brasileira por meio do intercâmbio e da mobilidade internacional, conforme esclarece o comunicado do parágrafo supra.

O programa CSF serviu, portanto, como alavanca para a internacionalização e, apesar de enfrentar atualmente a barreira da língua inglesa, empecilho para a grande maioria dos estudantes brasileiros, os processos de internacionalização permanecem fortes nas IES.

Faz-se importante relembrar que, quando o governo brasileiro iniciou o programa CSF para enviar 110.000 estudantes de Ciência, Tecnologia, Engenharia e Matemática para o exterior, descobriu que muitos deles não se qualificavam para o programa por terem um nível baixo de proficiência em inglês. Foi nesse momento, então, que o MEC, visando à permanência do crescimento do movimento de estudantes brasileiros rumo ao exterior, implementou o Inglês sem Fronteiras, que oferece cursos de inglês on-line para milhões de alunos universitários e exames TOEFL gratuitos para milhares de estudantes que desejam fazer um intercâmbio no exterior. No setor privado, grandes corporações internacionais estão comprando escolas privadas e fazendo o mercado de ensino de inglês crescer para três bilhões de dólares, o maior da América Latina.

Ademais, o Programa Inglês sem Fronteiras oferece, gratuitamente, cursos presenciais de Língua Inglesa aos alunos da graduação e, a partir de 2015, os servidores passaram a ser contemplados com o direito de concorrer para as vagas ofertadas nesses cursos, sendo que apenas os servidores que fizerem o TOEFL poderão participar, pois as notas obtidas servirão de teste de nivelamento para o ingresso (ou não) nas ações.

Esses dados corroboram a nossa assertiva no tocante ao espaço de hegemonia e prestígio que a língua inglesa ocupa nos cursos de graduação e pós- graduação, no Brasil e abrem espaços para debates acerca dos porquês da sua não oferta desde as séries iniciais na educação básica, onde, atualmente, segundo dados do ENEM, é a língua espanhola que tem sido a língua de escolha dos discentes que ingressarão nas universidades.

Na UFS, foi instituído o Exame de Proficiência em Língua Estrangeira (EPLE). 0 referido exame é aplicado duas vezes ao ano e pode ser usado nos processos seletivos de quaisquer programas de graduação da instituição. Sua validade é de dois anos, após os quais se faz necessária nova submissão dos candidatos às avaliações.

O inglês, neste contexto, desde a primeira edição do exame, em 2013, até o momento, tem sido a língua mais solicitada dentre as demais, quais sejam, o francês e o espanhol, conforme dados fornecidos pela Pró-Reitoria de Pós-Graduação e Pesquisa (POSGRAP) da instituição em tela, conforme podemos observar no Gráfico 1. 


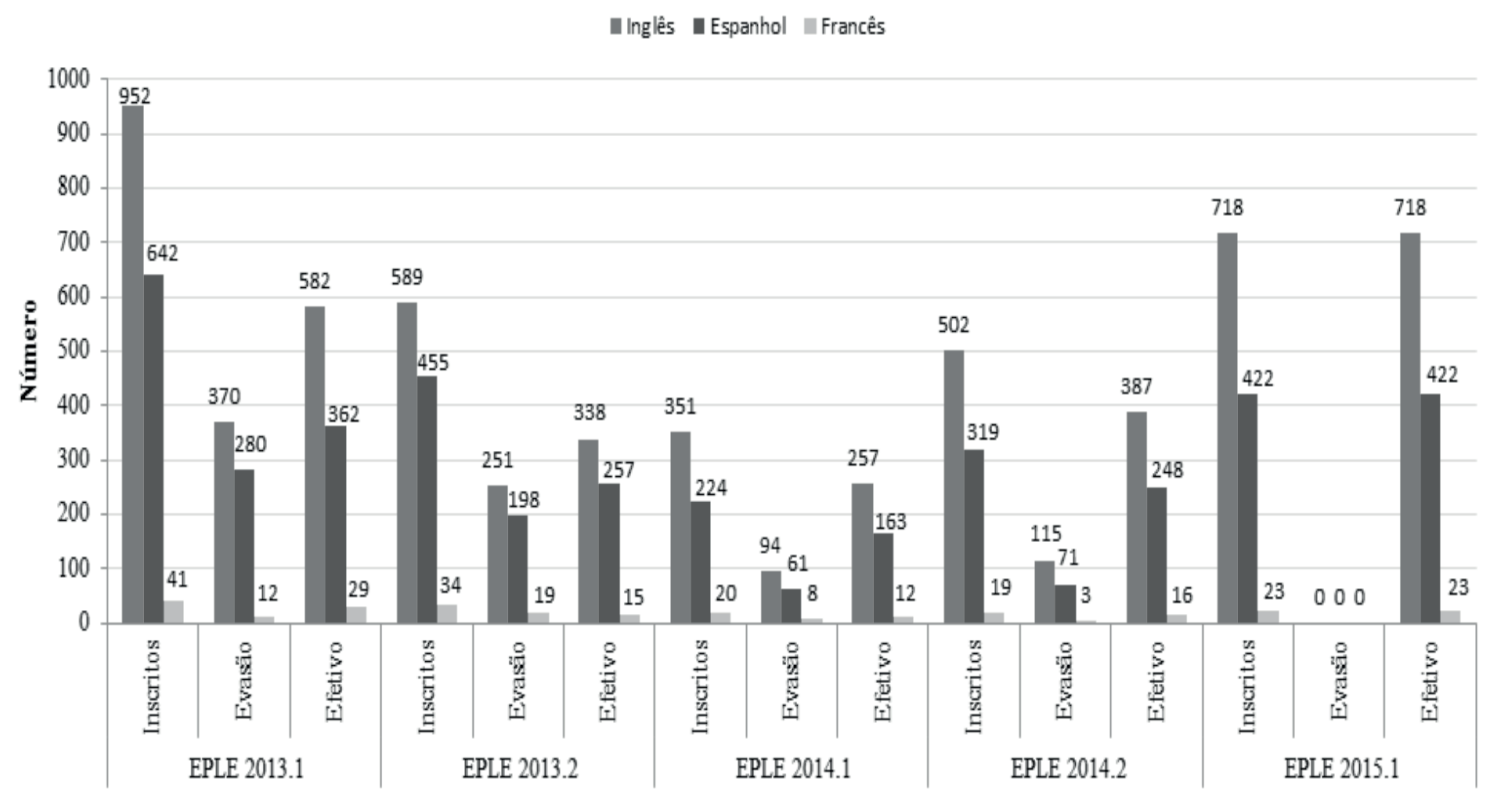

Fonte: Compilação pela autora de dados fornecidos pela Pró-Reitoria de Pós-graduação e Pesquisa UNIVERSIDADE FEDERAL DE SERGIPE.

Como vemos, apesar de o número de inscritos ter decrescido em algumas edições do teste, o inglês ainda se destaca como a língua mais escolhida desde a sua primeira aplicação.

\section{ESPANHOL: A LÍNGUA DA EDUCAÇÃO BÁSICA}

O ENEM é, atualmente, a avaliação em larga escala de maior impacto no Brasil. Devido às inúmeras funções atribuídas aos dados do exame, podemos dizer que ele tem sido decisivo no que diz respeito à regulamentação de novas reformas na educação, além de os seus resultados impactarem fortemente no nosso sistema educacional. A análise de uma série de dados de 1998, ano em que começa a ser aplicado o exame, até $2013^{1}$, mostra o relevo da língua estrangeira moderna e a escolha dos estudantes, pontuando outro tipo de avaliação: a de motivação e relevância atribuída à língua.

1. Os dados referentes a 2014 não puderam ser coletados em virtude de 0 arquivo disponível no site oficial estar corrompido. Os de 2015 ainda serão disponibilizados. 
Figura 2 - Gráfico da Porcentagem de Inscritos no ENEM de 2010 a 2013 - Classificados por Idioma Escolhido

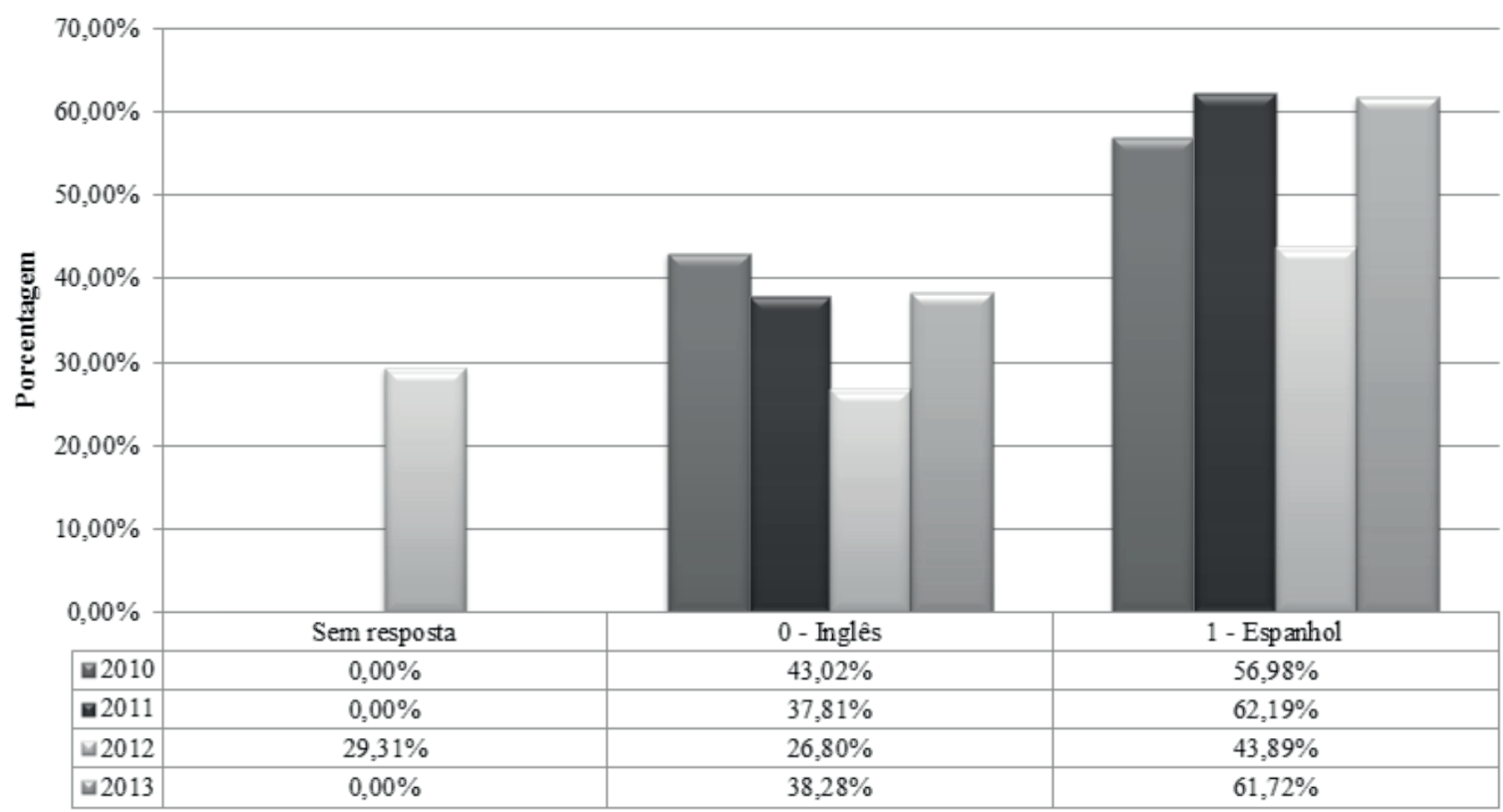

Fonte: Dados tabulados pela autora a partir da base disponibilizada pelo Instituto Nacional de Estudos e Pesquisas Educacionais Anísio Teixeira.

No Gráfico da Figura 2, observamos que em todas as edições do exame, a partir de 2010, quando começou a ser aplicada a prova de LE e ao aluno foi assegurado o direito de escolha pelo inglês ou pelo espanhol, a língua espanhola consta como a 'preferida', embora saibamos que, na prática das escolas, o inglês é a língua que prevalece.

Como vemos, especialmente nos três últimos anos, a escolha pelo espanhol tem expressivo aumento e isso nos leva à constatação de que, embora ainda não se saiba exatamente o porquê de os alunos - que no ensino fundamental e médio, na sua maioria, estudam o inglês - optarem pelo espanhol (preferência linguística, não domínio do inglês, dente outras possíveis causas ora sendo investigadas), os números têm o poder de tornar absolutamente inexpressivo e insignificante o fato de o inglês ser a língua mais ensinada nas escolas. $E$, caso isso aconteça, perguntamo-nos até quando, sem quaisquer políticas linguísticas explícitas, o inglês permanecerá nos currículos escolares.

Excetuando-se essa situação no que concerne ao ENEM, onde o inglês aparece em desvantagem, a sua importância está consolidada no mercado de trabalho global e o seu domínio constitui-se, em muitos casos, em requisito obrigatório de empregabilidade não apenas nos países de expressão oficial inglesa, mas também em outros países onde o idioma se converteu em segunda língua.

As vantagens conferidas aos que têm o domínio do inglês e o fato de que as famílias mais abastadas tendem a oferecer aos seus filhos uma iniciação precoce no que concerne aos estudos dessa língua, permitindo-lhes integrar-se socioculturalmente e possibilitando-lhes constantes ajustes no domínio das qualificações profissionais, bem como nos domínios cultural 
e científico, revelam-nos que há uma desigualdade flagrante em relação aos que não podem/poderão se beneficiar desse importante suplemento de formação caso continue a ocorrer a diminuição e/ou haja a exclusão da oferta do inglês no sistema educacional no Brasil, por motivos aqui já expostos.

\section{CONSIDERAÇÕES PRELIMINARES}

Como disse Leffa (2003), a história do ensino da língua inglesa tem-se caracterizado pela síndrome do pêndulo, movendo-se sempre da tese para a antítese, sem nunca chegar a uma síntese.

Chegarmos, portanto, à construção de uma síntese, parece-nos estar intrinsecamente relacionado às questões que envolvem a atual legislação da educação nacional, motivo pelo qual se torna necessário alavancar discussões sobre a necessidade de se implementar políticas linguísticas que explicitem qual é o papel do inglês na sociedade e que motivações levam os indivíduos a quererem aprendê-lo.

Por mais que a teoria tente demonstrar o contrário, tratando da hegemonia da língua inglesa e das suas importantes funções cognitivas, críticas, sociais, afetivas e culturais, o cenário e os discursos que temos hoje comprovam que ainda trabalhamos com a ideia de que aprender línguas é útil apenas para os que pretendem ir ao exterior; que inglês não se aprende na escola regular e que é melhor nos ocuparmos estudando coisas da nossa nação, ao invés das de países estrangeiros.

Com esses pensamentos, ignoradas têm sido as necessidades plurilíngues e culturais do nosso país, prejudicando o seu desenvolvimento socioeconômico, afetando segmentos diversos da sociedade, em particular os menos favorecidos como, por exemplo, os estudantes da rede pública de ensino, aos quais são negadas oportunidades de aperfeiçoamento in- dividual e, consequentemente, tiradas as chances para que tenham uma participação ativa nas sociedades hoje tão competitivas.

A guisa de conclusão, apesar de haver inúmeras ações em prol da língua inglesa, no universo da educação básica brasileira vemos o crescimento do ensino de espanhol que, ao contrário do inglês, com a Lei $n^{0} 11.161$, de 5 de agosto de 2005, tem assegurada a obrigatoriedade da sua oferta no ensino médio.

Mediante o exposto, não nos restam dúvidas de que a dissonância entre o que se preconiza como a língua do desenvolvimento e da ciência - como apontam as diretrizes do programa CSF - e a língua cuja oferta é obrigatória na educação básica é assunto ao qual atenção deve ser devotada.

\section{REFERÊNCIAS}

ALMEIDA FILHO, José Carlos P. de (Org.). O Professor de língua estrangeira em formação. 2.ed. Campinas: Pontes, 2005.

ARRETCHE, Marta Teresa da Silva. Tendências no estudo sobre avaliação. In: RICO, Elizabeth Melo (Org.). Avaliação de políticas sociais: uma questão em debate. 6.ed. São Paulo: Cortez, 2009.

BOURDIEU, Pierre. et. al. Quelles langues pour une

Europe démocratique? Paris: Presses de Sciences Po (P.F.N.S.P.), 2001. Disponível em: <https://www.cairn. info/revue-raisons-politiques-2001-2-page-41.htm>. Acesso em: 28 Set. 2015.

\section{CONSELHO DA EUROPA. Quadro europeu comum} de referência para as línguas. Aprendizagem, ensino, avaliação. Direção: José Matias Alves. Porto: Edições Asa, 2001. (Coleção: Perspectivas Actuais/ Educação). ISBN 972-41-2746-X. 
COSTA. D. N. M. Por que ensinar língua estrangeira na escola de $\mathbf{1}^{\circ}$ grau. São Paulo: EPU/EDU, 1987.

COUTELLE, José Eduardo. Rumo ao Exterior. Revista Ensino Superior, 204.ed., 2015.

FREITAG, Raquel Meister Ko. et al. Impacto da prova de redação do Enem no currículo escolar da rede estadual de Sergipe. Aracaju: Universidade Federal de Sergipe, 2015. 94p.

LE BRETON, J. Reflexões anglófilas sobre a geopolítica do inglês. In: LACOSTE, Yves; RAJAGOPALAN, Kanavillil (Org.). A geopolítica do inglês. São Paulo: Parábola Editorial, 2005.
LEFFA, Vilson J. O ensino de línguas estrangeiras no contexto nacional. Revista Contexturas, n.4, [S.I.]: APLIESP, 1999. p.13-24.

LEFFA, Vilson J. Língua estrangeira hegemônica e solidariedade internacional. In: KARWOSKI, Acir Mário; BONI, Valéria de Fátima Carvalho Vaz (Org.). Tendências contemporâneas no ensino de inglês. União da Vitória-PR: Kaygangue, 2006. p.10-25

RAJAGOPALAN, Kanavilil. A Geopolítica da Língua Inglesa e seus Reflexos no Brasil: por uma política prudente e propositiva. In: LACOSTE, Y.; RAJAGOPALAN, Kanavilil (Org.). A geopolítica do inglês. São Paulo: Parábola, 2005. p.135-159. 
